\title{
BMJ Open Quality improvement and person- centredness: a participatory mixed methods study to develop the 'always event' concept for primary care
}

Paul Bowie, ${ }^{1,2}$ Duncan McNab, ${ }^{1,3}$ Julie Ferguson, ${ }^{1}$ Carl de Wet, ${ }^{1}$ Gregor Smith, ${ }^{4,5}$ Marion MacLeod, ${ }^{1}$ John McKay, ${ }^{1}$ Craig White ${ }^{6,7}$

To cite: Bowie $P$, McNab D, Ferguson J, et al. Quality improvement and personcentredness: a participatory mixed methods study to develop the 'always event' concept for primary care. BMJ Open 2015;5:e006667. doi:10.1136/bmjopen-2014006667

- Prepublication history for this paper is available online. To view these files please visit the journal online (http://dx.doi.org/10.1136/ bmjopen-2014-006667).

Received 18 September 2014 Revised 27 January 2015 Accepted 13 February 2015

CrossMark

For numbered affiliations see end of article.

Correspondence to

Dr P Bowie;

paul.bowie@nes.scot.nhs.uk

\section{ABSTRACT}

Objectives: (1) To ascertain from patients what really matters to them on a personal level of such high importance that it should 'always happen' when they interact with healthcare professionals and staff groups. (2) To critically review existing criteria for selecting 'always events' (AEs) and generate a candidate list of AE examples based on the patient feedback data.

Design: Mixed methods study informed by participatory design principles.

Subjects and setting: Convenience samples of patients with a long-term clinical condition in Scottish general practices.

Results: 195 patients from 13 general practices were interviewed $(n=65)$ or completed questionnaires $(n=130) .4$ themes of high importance to patients were identified from which examples of potential 'AEs' $(n=8)$ were generated: (1) emotional support, respect and kindness (eg, "I want all practice team members to show genuine concern for me at all times"); (2) clinical care management (eg, "I want the correct treatment for my problem"); (3) communication and information (eg, "I want the clinician who sees me to know my medical history") and (4) access to, and continuity of, healthcare (eg, "I want to arrange appointments around my family and work commitments"). Each 'AE' was linked to a system process or professional behaviour that could be measured to facilitate improvements in the quality of patient care.

Conclusions: This study is the first known attempt to develop the AE concept as a person-centred approach to quality improvement in primary care. Practice managers were able to collect data from patients on what they 'always want' in terms of expectations related to care quality from which a list of AE examples was generated that could potentially be used as patientdriven quality improvement $(\mathrm{QI})$ measures. There is strong implementation potential in the Scottish health service. However, further evaluation of the utility of the method is also necessary.

\section{INTRODUCTION}

Over 2000 years ago (ca. 460-370 BC), Hippocrates taught that "It is more important

\section{Strengths and limitations of this study}

- The study demonstrated the potential to explicitly link the quality improvement and personcentredness agendas using the 'always event' concept in primary care with a focus on patients with long-term conditions.

- A proof-of-principle was established in terms of the feasibility of this method in collecting relevant data from patients that could inform 'always event' generation, and linking this to measureable elements of practice systems and team behaviours. However, more research is required to determine if this can actually drive sustainable quality improvements in care processes.

- The study was small, focused on a specific patient subpopulation, and involved volunteer managers from interested general practices. A larger study which is more representative of practice types, locations and patient populations is necessary, alongside exploring the potential to test the concept in other health sectors.

to know what sort of person has a disease than to know what sort of disease a person has." Recently, continuing advances in medical science and technology have contributed to major achievements in disease prevention and effective clinical care management, and also to the creation of a clinician and disease-centred model of healthcare. ${ }^{1-3}$ Consequently, there is now a growing recognition of the essential need to take a 'person-centred' approach to further improving service quality, clinical outcomes, and the patient's experience. ${ }^{4-6}$ While a raft of patient experience and satisfaction surveys are available, ${ }^{7}$ routinely capturing meaningful feedback from the patient's perspective is problematic and is only the first step in further improving the quality and safety of healthcare. $^{8-12}$

The 'always event' (AE) concept (originally developed by the US-based Picker Institute ${ }^{13}$ ) 
offers a person-centred approach to quality improvement (QI) that may further optimise different aspects of the patient's experience of their healthcare, and which can potentially be used routinely within many care settings. An 'AE' can be defined as ".... clear, action-oriented and pervasive practice or set of behaviours that, when implemented reliably, will ensure an optimal patient and family experience and improved outcomes." ${ }^{14}$ A simple example might be that a patient "always wants to know what happens next" after a clinical consultation. In other words, AEs are those actions and behaviours of healthcare organisations, teams, professionals and staff that create a satisfactory experience for patients. ${ }^{15}$

The AE method is strongly rooted in identifying and considering quality-of-care issues that are highlighted by patients, families and carers as being of great importance to them personally. It 'plays opposite' to, but is correlated with the systems-centred development and implementation of Never Event lists (of serious patient safety incidents that should never happen if the appropriate mitigation strategies are in place) to facilitate the reporting of adverse events and near misses, collective learning and improvement to make healthcare safer. ${ }^{1617}$

However, a key feature of the $\mathrm{AE}$ approach is its 'open architecture' in preference to a discrete and prescriptive list of 'AEs' for all or even specific care settings. ${ }^{13}$ The perceived advantage of an 'open' engagement approach is that organisations and teams can identify and contextualise their own patients' priorities, and also adapt AEs to a constantly changing healthcare environment. Application of the same engagement process will, therefore, most likely produce different lists of AEs which are of great importance to the care-related needs and wants of specific local patient groups.

A recent review of empirical studies concerned with measuring patient experience, ${ }^{7}$ and a general search of common bibliographic databases does not appear to highlight any examples of the $\mathrm{AE}$ approach in the published literature. However, a number of funded research programmes are reportedly underway ${ }^{18}$ in US-based healthcare settings focused on, for example, overcoming the improvement challenges associated with patient-provider communication issues, pain control and comfort, and the prevention of falls.

Against this background, therefore, the purpose of this study was to ascertain from patients in a primary care setting what really matters to them on a personal level of such high importance that it should 'always happen' when they interact with healthcare services, professionals and staff groups. Furthermore, we aimed to critically review the applicability of existing criteria for selecting AEs $^{13}{ }^{14}$ to the Scottish primary care context, before generating examples of AEs based on the patient feedback study data collated, and demonstrating how these could potentially be implemented for QI purposes.
Box 1 Conceptual definitions and principles

\section{Quality Improvement ${ }^{32}$}

The conception of improvement finally reached... was to define improvement as better patient experience and outcomes achieved through changing provider behaviour and organisation through using a systematic change method and strategies

Person-centred care ${ }^{33}$

Health Foundation framework comprising four principles of personcentred care

1. Affording people dignity, compassion and respect

2. Offering coordinated care, support or treatment

3. Offering personalised care, support or treatment

4. Supporting people to recognise and develop their own strengths and abilities to enable them to live an independent and fulfilling life

\section{METHODS}

\section{Conceptual definitions and principles}

While a simple operational definition of what is understood by 'QI' in healthcare is readily available, adequately defining 'person-centredness' is arguably more problematic because it is an emerging and evolving concept. In recognising this definitional limitation, the UK Health Foundation has identified a framework that comprises four principles of person-centred care which should underpin any improvement intervention (box 1).

\section{Setting}

\section{Scottish general medical practices}

\section{Study design, subjects and data collection}

A mixed methods study, informed by participatory design principles, ${ }^{19}$ utilising brief semistructured interviews and short cross-sectional questionnaire surveys was conducted with convenience samples of patients identified as having a long-term clinical condition (eg, type II diabetes, or chronic pulmonary obstructive disease) over a 1-week period in April 2014. Participatory design is a flexible user-centred approach which attempts to actively involve all relevant stakeholders (eg, patients, healthcare professionals, policymakers, researchers and academics) in the design process, so that the outcome meets their needs, and both feasibility and usability are enhanced. ${ }^{20}$

Prior to this, three groups of practice managers were emailed with study details and asked to volunteer to participate: group 1 were members of the National Learning and Development Network of practice managers, and groups 2 and 3 were based in NHS Ayrshire and Arran and NHS Lanarkshire health board areas, respectively. Participating managers conducted a brief interview with five consenting patients, and recruited a further 10 consenting patients to self-complete a short questionnaire while attending practice appointments. A dual purpose data collection proforma (to prompt interview questions and use as a questionnaire survey) consisting of three interlinked questions was adapted by the authors from similar work ${ }^{1314}$ for these tasks (box 2). 
Box 2 Questions used in brief semistructured interviews and the questionnaire survey of patients

Q1. What matters to you about the care you receive from your surgery?

Q2. What do you feel is so important that it should ALWAYS happen when you have contact with your doctor's surgery?

Q3. Please complete this sentence: The care I receive would be better if..

\section{Data analysis}

Qualitative and quantitative data were uploaded to an Excel spreadsheet, treated as a single dataset and subjected to basic content analysis ${ }^{21}$ or descriptive statistical analysis by JF. For the qualitative data, themes and subthemes of relevance were then generated, which were checked against the original data sources by PB. Disagreements were resolved by joint checking of data and themes to reach consensus.

\section{Redesign and application of 'AE' criteria}

A development group (consisting of frontline general practitioners (GPs), a practice manager educator, clinical and health psychologists, GP educators and QI experts) adapted the existing selection criteria ${ }^{13}{ }^{14}$ by applying similar validation methods to those used for generating Never Events ${ }^{17}$ to make them more relevant and feasible for Scottish primary care settings. The adapted criteria were then applied jointly by three authors (DM, PB and CdW) to the study themes and linked quotations to generate potential AEs. This was achieved by developing a potential AE statement that was explicitly based on the verbatim phraseology and words used by patients, and which was judged by the three authors to best reflect the findings summarised in that specific study theme-a pragmatic and subjective task that practice teams will have to undertake to generate local AEs with a degree of face validity. Each generated $\mathrm{AE}$ was then linked to practice systems or professional behaviours that were potentially amenable to routine measurement for QI purposes. The wider group then considered the adapted criteria and potential AEs, and discussed their relevance, clarity and feasibility via electronic mail and face-to-face discussions on an iterative basis until consensus was reached on a final candidate list of $\mathrm{AE}$ examples.

\section{RESULTS}

\section{Response rate and demographics}

Thirteen general practices participated, which equates to 65 patient interviews and questionnaire completion by a further 130 patients $(n=195)$. The demographic characteristics of participating practices are outlined in table 1.

The following four themes of high importance to patients were identified.

\section{Emotional support, respect and kindness}

It was of great importance to patients that all the clinical and administrative staff they interacted with smiled, adopted a friendly attitude towards them and acted in a pleasant and polite manner. Patients want to be treated with full respect on a personal, empathic basis as distinct individuals at all times by staff groups, rather than feel they were 'just a number' or 'just another patient'.

It should be friendly and efficient and I should always be No.1

All staff should be polite and pleasant towards patients

That you are treated with respect at all times

Being treated as an individual—not next in line, but don't feel this is a problem

Someone shows genuine concern for any matter that I present with.

\section{Clinical care management}

How their problems, diagnosis and illness are managed was viewed as an important care priority by patients. For example, that symptoms are not ignored, that healthcare professionals are knowledgeable about their condition and its treatment, and that patients feel confident in the

Table 1 Demographics and characteristics of participating general practices $(n=13)$

\begin{tabular}{lc}
\hline & $\begin{array}{l}\text { Participating } \\
\text { general } \\
\text { practices (n) }\end{array}$ \\
Practice factors & \\
\hline Participating health boards & 4 \\
NHS Ayrshire and Arran & 2 \\
NHS Greater Glasgow and Clyde & 2 \\
NHS Highland & 4 \\
NHS Lanarkshire & 1 \\
NHS Shetland & \\
Training practice accreditation & 9 \\
Yes & 4 \\
No & 2 \\
Type of practice & 3 \\
Remote and rural & 8 \\
Semi-rural & 0 \\
Urban & \\
Inner city & 5 \\
Size of practice population & 3 \\
<5000 & 10 \\
$50001-10000$ & 3 \\
$>10000$ & 12 \\
Active patient participation group & \\
Yes & \\
No & \\
Routine patient input to practice developments \\
Yes & 3 \\
No & \\
\hline & \\
&
\end{tabular}


skills and expertise of clinical staff. Specifically, they identified that it was important to them that clinical conditions are diagnosed correctly and in a timely manner, and that the treatment given is always appropriate to the condition.

The correct treatment in accordance with my past medical history

That I receive it when I want it. It is free and I do not have to pay for it. It is delivered quickly. It is given to me by people who are properly qualified and understand my needs

It matters a lot to me that I receive good care which I do, as this allows me to continue working and doing the many things I do.

\section{Communication and information}

It was important for patients that they felt able to speak freely to healthcare professionals about their condition, and that they were being genuinely listened to. Similar views were expressed in terms of the importance of being engaged by, and listened to by frontline reception and administrative staff. It was important also for patients to have their problems, test results, diagnosis, treatment and prognosis explained in a timely manner and in a way that is clearly understood by them, but is not patronising.

That you can ask the GP anything you need to and to understand what they say because they are saying it using word and language you understand. That they talk to you, not look at the book or computer...

The appreciation by reception staff that patients (more often than not) actually do need some consultation with someone whom they find approachable and whose diagnoses and judgement they trust

I feel that when I leave the surgery that I have had a positive outcome e.g. any questions that I had have been answered and even more importantly that I have been listened to.

\section{Access to, and continuity of, healthcare}

Being able to easily contact the surgery to make an appointment was mentioned by a majority of participants as being of great importance to them. However, some participants stated that at certain times of the day, for example, in early morning, it was difficult to access an appointment by telephone and this was a continual source of frustration. The ability to make appointments for a time that suits the patient was frequently mentioned as important to them, whether it is on the same day, within $48 \mathrm{~h}$ or a few weeks in advance. Being seen by the GP or practice nurse close to the time of the allocated appointment time, and not being kept waiting, was also viewed as important. Being able to request to be seen by a specific doctor or nurse on a routine basis was important for many patients, particularly given their long-term clinical conditions.

The ability to book appointments in advance with a GP of my choice and at a time convenient to me

Being able to arrange appointments around work and family commitments

That we are able to access a doctor or practice nurse 'on the day' for important problems...

Prefer to see same GP every time and if given bloods want to know exactly what the results are...

That I should be able to see the nurse/doctor I always see and have confidence in...

\section{Candidate AE list}

A preliminary candidate list of eight 'AEs' was generated (table 2) based on the redesigned selection criteria (table 3) that were applied to the feedback data from patients. Each AE was linked to how it could be perceived by patients in everyday 'real-life' interactions with the practice together with suggestions on how practices could facilitate related measurement for improvement using existing or new systems or processes.

\section{DISCUSSION}

To the best of our knowledge, this small study is the first known attempt to develop and refine the $\mathrm{AE}$ concept in the primary care context. ${ }^{7}$ The outcomes strongly suggest that this method can translate to the primary care setting, that is, practice managers were able to collect data from patients on what they 'always want' in terms of expectations and desires related to care quality in general practice, which can potentially inform the development of localised lists of AEs or, for example, related care bundles. However, the identification of 'AEs' is only the first step in their use as a potential QI method. The next step involves practices implementing changes and measuring performance to ensure that AEs consistently occur. Further evaluation of this process, including identification of educational needs for practices, will also be necessary.

The study also provided an opportunity to reflect upon, refine and contextualise the original definitional criteria for selecting AEs ${ }^{13}{ }^{14}$ for potential implementation in the Scottish primary care setting. This allowed us to generate a candidate list of $\mathrm{AE}$ examples based on the patient data collected, but we do not suggest that these should necessarily be considered for use by practices as we undertook this task more as a 'proof of principle'. The preliminary events we arrived at are merely offered as examples to illustrate how a care team can implement a flexible process and apply the selection criteria to derive possible AEs of interest. The implication is that this can then help drive person-centred QI which 


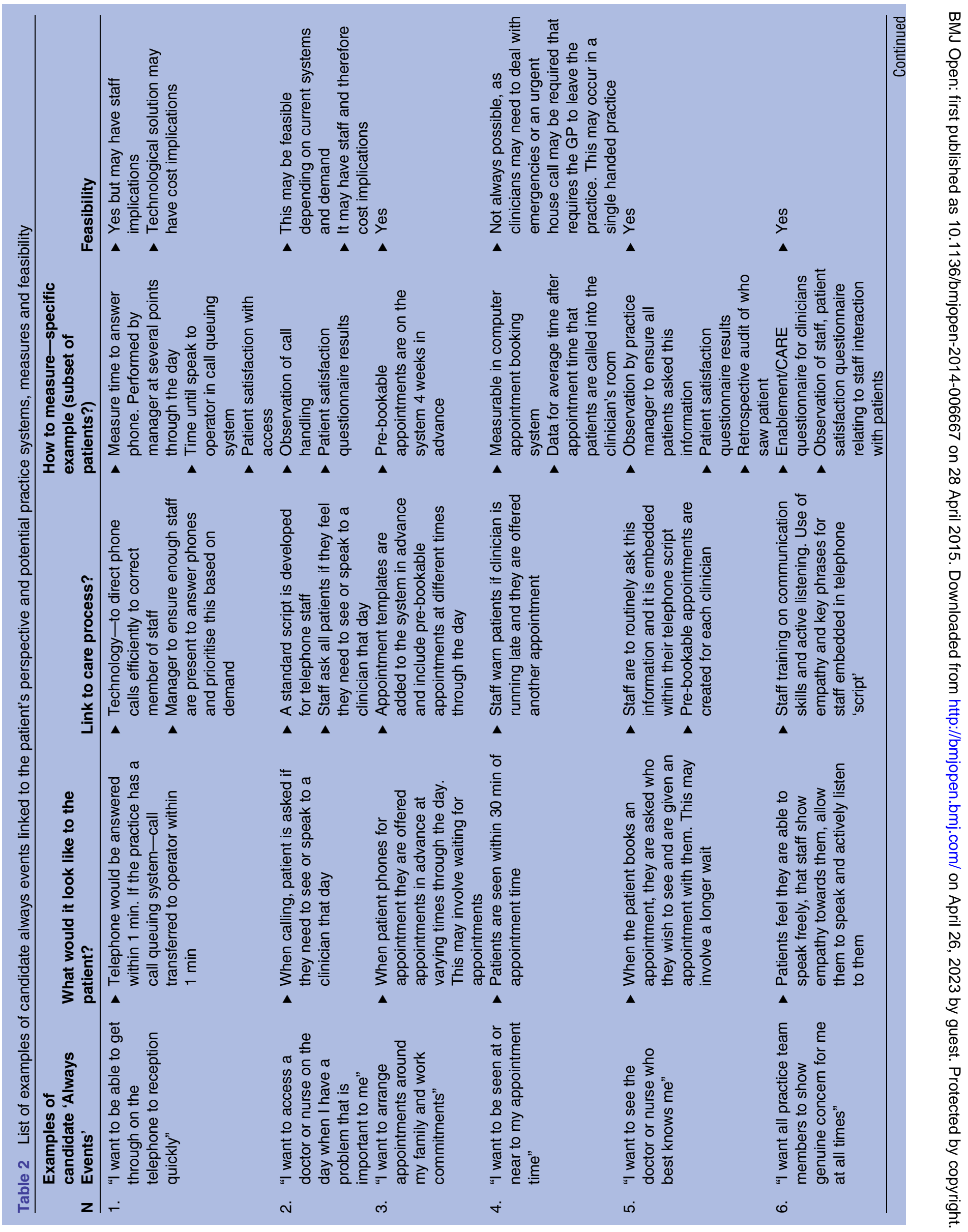




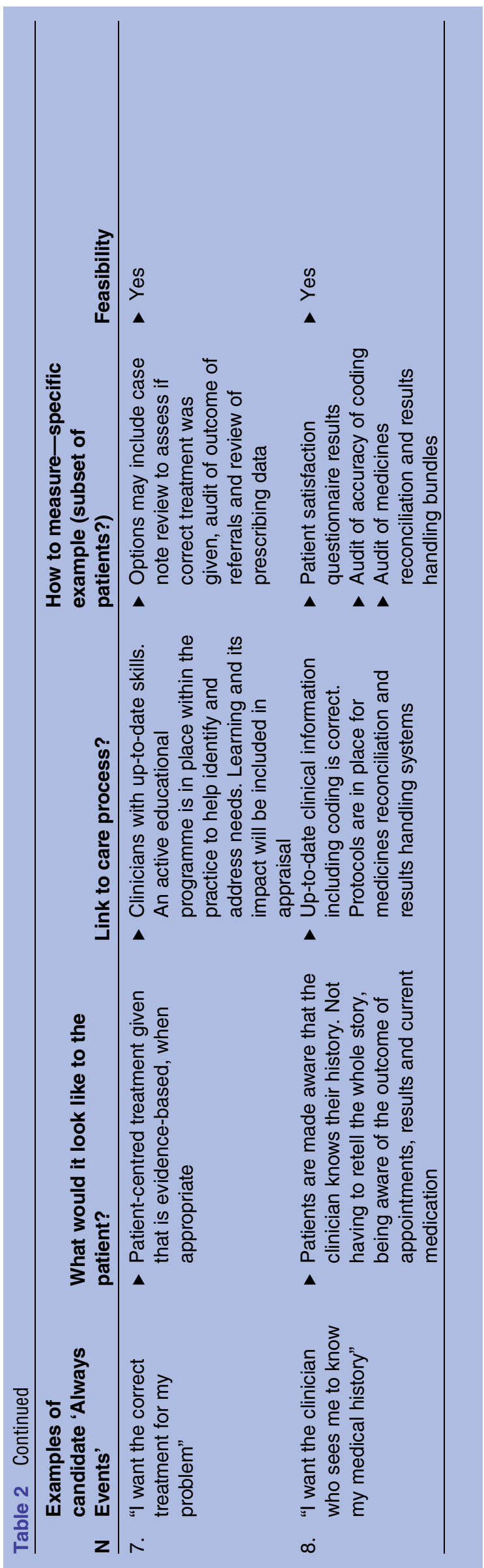

is directly linked to measureable elements of professional behaviours and healthcare processes.

A possible tension exists over whether AEs should be applicable to all patients in every circumstance, or to select subgroups of patients similar to this study's focus on those with long-term clinical conditions. For example, for some patients, being actively involved in deciding their care management or being provided with very detailed information about their condition would be an 'AE', but for others this may not be their preference and they may actually wish for the opposite. However, the findings show that, if we take the communication issues highlighted as examples, there are two distinct aspects which may have universal application: how patients are spoken to by administrative staff (both courtesy and respect), and also that the clinician really listens and finds out what is important to the patient (a reminder to be patient-centred). But achieving this 'universality' will be problematic given the difficulties in providing consistently high-quality healthcare in complex sociotechnical systems. ${ }^{22}$ It may be more pragmatic, therefore, to view an 'AE', like a 'never event', as being aspirational rather than something that can 'always' be delivered or, alternatively, look to amend the terminology to reflect a more realistic approach and definition.

A potential difficulty also exists in determining how AEs can be used in routine practice. The themes identified in this study appear consistent. Some may find them non-specific and high level; however, it may not be immediately obvious to all staff that they form the basis of fundamental good care. The other interpretation is that we have demonstrated how care teams can potentially perform this activity themselves and develop actions for improvement. Therefore, producing a list of AEs from our data may be useful as an example to practices of how to use this approach. They may want to perform a similar listening exercise and develop a localised list of more specific AEs-for example, in our study one patient stated "I want to see a senior doctor when needed," another said "telephone access" was important while another suggested it was important to "check date of birth." It is possible that these patients have identified specific problems in their practices which the proposed method could be used to address. Adopting this type of 'bottom-up' listening approach may lead to greater and more meaningful engagement and sustainability.

Based on professional workplace and research experiences, it was felt necessary to revise, broaden (to include carers and relatives as well as patients and clients) and contextualise the existing $\mathrm{AE}$ selection criteria for a number of pragmatic reasons. The first is that the criterion 'evidence-based' was omitted because it was agreed that if patients indicate they perceive an experience as important (criterion 1), it automatically 'trumps' the requirement to demonstrate that the potential ' $\mathrm{AE}$ ' is 'related to optimal care'. In other words, this should then be accepted as a 'given' until proven otherwise. 
Table 3 Comparison of original and redesigned selection criteria for always events (AEs)

\section{Original AE selection criteria}

1. Important: Patients have identified the experience as fundamental to their care

2. Evidence-based: The experience is known to be related to the optimal care of, and respect for, the patient

3. Measurable: The experience is specific enough that it is possible to accurately and reliably determine whether or not it occurred

4. Affordable and sustainable: The experience can be achieved by any organisation without substantial renovations, capital expenditures or the purchase of new equipment or technology

NES, NHS Education for Scotland.
Redesigned AE selection criteria by NES development group

An Always Event...

1. Is any healthcare interaction, process or outcome that is judged by patients, carers or relatives to be a highly important determinant of care quality and experience; AND

2. Is unambiguous and specific to enable reliable measurement; AND

3. Is consistently deliverable to applicable patient groups by all relevant healthcare organisations, teams and individuals; AND

4. Is feasible as part of routine healthcare delivery
Additionally, the 'evidence-base' criterion may lead to the premature exclusion of potentially useful AEs, given the relative lack of evidence for some healthcare interventions in different settings.

A further difference is the addition of the criterion that an AE "can consistently be delivered...to every patient by all relevant individuals..." In other words, for a care interaction, process or outcome to be an 'AE', its successful delivery should be completely operator dependent. For example, consider the following potential 'AE' that a patient proposed: "The person I speak to has access to my records..." The statement fulfils three of the four selection criteria: it is of importance to the patient and it is unambiguous, measurable and potentially feasible. However, factors outwith a clinician's control may make it impossible to deliver this experience and expectation at all times (eg, interruption to power supply to the practice, hardware issues, or human-computer interaction problems). The final difference is that the criterion 'affordable and sustainable' was reworded as 'feasible' (ie, 'possible and practical to do easily or conveniently'). Feasibility includes affordability and sustainability but also time, weighting of competing priorities and consideration of local contextual influencers.

\section{Comparison with existing literature}

Our findings are comparable with the research undertaken by the Picker Institute, which informed development of the AE concept. ${ }^{23-25}$ They found that patients' 'wants' from healthcare are universal and consistent and include: (1) easy access to coordinated, integrated care; (2) effective communication; (3) reliable, understandable and useful information; (4) physical comfort, emotional support, and to be treated with respect; (5) continuity/seamless transitions and (6) involvement of family and friends. So, while our findings are not unique and are arguably rather 'obvious', they do have value, because in addition to explicitly linking the person-centredness and QI agendas, there is very limited empirical data related to what patients actually want and expect from high-quality general practice care. ${ }^{7} 8$

\section{Strengths and limitations}

One of the principles of the $\mathrm{AE}$ approach reflected in the study design is that improvements are informed by the desires and preferences of patients, rather than on the assumptions of care providers about their wants and needs. A specific strength of the study, therefore, is the participatory design method adopted which involved the co-development and testing of the $\mathrm{AE}$ process in a partnership between patients, managers, clinicians, educators and academic leaders representing a range of frontline groups, health authorities, educational organisations and national government. We also adopted a pragmatic but methodical approach to rapid data collection, analysis and consensus building to add a degree of rigour to the process. Finally, we focused on patients with long-term clinical conditions because they have good experience and knowledge of care process interactions with GP surgeries, healthcare professions and staff which would be beneficial to our study aims.

The limitations include the potential for bias from over-representation of practices with specialty training accreditation, and the use of a small convenience sample of volunteer enthusiasts. Including broader groups of patients who were more representative of local GP populations may have identified other issues of importance to them. Patients may not have been as forthcoming in terms of offering views on what is important to them because of the data collection methods employed, for example, practice managers were not trained in interview techniques, while short questionnaires may not be the most rigorous method for capturing this type of largely qualitative data. Additionally, we did not collect data on how many patients in total were approached before the requested interview and survey numbers were achieved. A more in-depth qualitative approach using purposive samples of patients may have yielded deeper insights. 
Potential implementation of the AE method

In terms of developing a process to measure compliance with selected AEs as a means to monitor and drive improvements in patient experience and care quality, then it is possible that the "care bundle ${ }^{26}$ method (eg, around the respect and kindness theme highlighted in this study or related local issues identified by practices) could be usefully linked to feedback from patient survey tools or internal observations of staff behaviours, or from existing patient opinion infrastructure.

The person-centredness and QI agendas ${ }^{47}$ form a key (but underdeveloped) element of, for example, general practice specialty training, ${ }^{28}$ medical appraisal and regulation, ${ }^{29}$ the Scottish Patient Safety Programme, ${ }^{30}$ the pay-for-performance Quality and Outcomes Framework, ${ }^{31}$ and arrangements for continuing professional development in the UK, thereby providing a range of potential opportunities to introduce the $\mathrm{AE}$ method into routine healthcare practice as part of existing educational and QI obligations. However, it is clear that care teams will require educational support to develop processes to help them collect relevant data, identify AEs, measure compliance and make meaningful improvements in care within their own work contexts.

\section{CONCLUSIONS}

This small study has taken the first steps in establishing a 'proof of principle' for 'AEs' as a person-centred QI method in this primary care setting, and providing some evidence of the possibilities. We would support the 'open architecture' concept of empowering local care teams to engage with their patient populations to co-develop and test their own priority AEs, but also share access to these examples as part of developing a wider person-centred community of practice within healthcare-a key development stage of the $\mathrm{AE}$ programme that is recommended. ${ }^{13} 14$

Although it is clear that there is strong implementation and spread potential with regard to embedding the $\mathrm{AE}$ approach within and across a range of educational, safety improvement and contractual initiatives in the Scottish health service, further testing and evaluation of the utility of this care improvement method with more diverse patient groups, general medical practices and other health sectors is clearly necessary.

\author{
Author affiliations \\ ${ }^{1}$ Department of Postgraduate GP Education, NHS Education for Scotland, \\ Glasgow, UK \\ ${ }^{2}$ Institute of Health and Wellbeing, University of Glasgow, Glasgow, UK \\ ${ }^{3} \mathrm{NHS}$ Ayrshire \& Arran Health Board, UK \\ ${ }^{4} \mathrm{NHS}$ Lanarkshire Health Board, UK \\ ${ }^{5}$ Primary Care Division, Population Health Improvement Directorate, Scottish \\ Government, Edinburgh, UK \\ ${ }^{6}$ Healthcare Quality \& Strategy Directorate, Scottish Government, UK \\ ${ }^{7}$ School of Health, Nursing and Midwifery, University of the West of \\ Scotland, UK
}

Twitter Follow Gregor Smith at @gissymedman
Acknowledgements The authors would like to offer sincere thanks to all the patients who kindly participated in this study; Mrs June Morrison of NHS Education for Scotland for administrative support; and the following practice managers for assisting with recruitment, data collection and project coordination: Fiona Harris, Jan McCulloch, Marion McCallum, Elsbeth Miller, Sarah Morrow, Eileen Singleton, David Sweeney, Ann Wilson, Elizabeth Williamson, Kevin Wood, Jaqueline Wright, Lorraine Goldie and Mairi Dunnings.

Contributors PB contributed to the conception, funding, recruitment, research management, criteria development, initial drafting and critical revision of the manuscript. DM contributed to the recruitment, data analysis, criteria development and critical revision of the manuscript. JF contributed to the research management, data analysis and critical review of the manuscript. GS and MM contributed to the recruitment, criteria development and critical revision of the manuscript. CdW and CW contributed to the conception, criteria development and critical review of the manuscript. JM contributed to the data analysis and critical review of the manuscript.

Funding NHS Education for Scotland.

Competing interests None declared.

Ethics approval Pre-screened by the west of Scotland research ethics committee and judged to be service evaluation.

Provenance and peer review Not commissioned; externally peer reviewed.

Data sharing statement No additional data are available.

Open Access This is an Open Access article distributed in accordance with the Creative Commons Attribution Non Commercial (CC BY-NC 4.0) license, which permits others to distribute, remix, adapt, build upon this work noncommercially, and license their derivative works on different terms, provided the original work is properly cited and the use is non-commercial. See: http:// creativecommons.org/licenses/by-nc/4.0/

\section{REFERENCES}

1. McWhinney IR. Patient-centred and doctor-centred models of clinical decision making. In: Sheldon M, Brook J, Rector A, eds. Decision making in general practice. London: Stockton, 1985:31-46.

2. Illingworth R. What does 'patient-centred' mean in relation to the consultation? Clin Teach 2010;17:116-20.

3. Epstein RM, Fiscella K, Lesser CS, et al. Why the nation needs a policy push on patient-centered health care. Health Aff (Millwood) 2010;29:1489-95

4. NHS Scotland. The healthcare quality strategy for NHS Scotland. Edinburgh: Scottish Government, 2010.

5. Committee on Quality of Health Care in America. Institute of medicine crossing the quality chasm: a new health system for the 21st century. Washington, DC: National Academy Press, 2001.

6. Department of Health. Creating a patient-led NHS: Delivering the NHS Improvement Plan. Crown, 2005. Report No 265602.

7. Health Foundation. Measuring patient experience. London: Health Foundation, 2013

8. Asprey A, Campbell JL, Newbould J, et al. Challenges to the credibility of patient feedback in primary healthcare settings: a qualitative study. Br J Gen Pract 2013;63:200-8.

9. Coulter A, Ellins J. Effectiveness of strategies for informing, educating, and involving patients. BMJ 2007;335:24.

10. Health Foundation. Involving patients in improving safety. London: Health Foundation, 2013.

11. Paddison C, Elliott M, Parker R, et al. Should measures of patient experience in primary care be adjusted for case mix? Evidence from the English General Practice Patient Survey. BMJ Qual Saf 2012;21:634-40.

12. Davies E, Cleary PD. Hearing the patient's voice? Factors affecting the use of patient survey data in quality improvement. Qual Saf Health Care 2005:14:428-32.

13. Picker Institute. Always events: creating an optimal patient experience, October 2011. http://alwaysevents.pickerinstitute.org/ (accessed 5 Apr 2014).

14. Institute of Healthcare Improvement. Always events initiative. http:// www.ihi.org/engage//nitiatives/PatientFamilyCenteredCare/Pages/ AlwaysEvents.aspx (accessed 5 Apr 2014). 
15. Always Events Getting Started Kit. Cambridge, MA: Institute for Healthcare Improvement, 2014. http://www.ihi.org (accessed $10 \mathrm{Jul}$ 2014).

16. de Wet C, O'Donnell C, Bowie P. Development of a preliminary 'never event' list for general practice using consensus building methods. Br J Gen Pract 2014;64:e159-67.

17. Department of Health. The "Never Events" list for 2011/12. London: Department of Health, 2011.

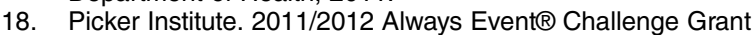
Recipient Project Overviews. http://alwaysevents.pickerinstitute.org/? $\mathrm{p}=548$ (accessed 20 Jul 2014).

19. Kensing F, Blomberg J. Participatory design: issues and concerns. Comput Support Cooper Work 1998;7:167-85.

20. Schuler D, Namioka A. Participatory design: principles and practices. Hillsdale, NJ: CRC Press, 1993.

21. Graneheim UH, Lundman B. Qualitative content analysis in nursing research: concepts, procedures and measures to achieve trustworthiness. Nurse Educ Today 2004;24:105-12.

22. Carayon P, Alvarado CJ, Hundt AS. Work system design in healthcare. In: Carayon $\mathrm{P}$, ed. Handbook of human factors and ergonomics in health care and patient safety. 2nd edn. Boca Raton, FL: CRC Press, 2012:65-79.

23. Picker Institute Europe \& University of Oxford. Developing measures of people's self-reported experiences of integrated care. http://www. pickereurope.org/assets/content/pdf/News\%20releases/Developing\% 20measures\%20of\%20IC\%20report_final_07012014.pdf (accessed 20 Jul 2014).

24. Redding $\mathrm{D}$. The narrative for person-centred coordinated care. J Integr Care 2013;21:315-25.
25. HCAHPS Executive Insight. Hcahpsonline.org. Baltimore, MD: Centers for Medicare \& Medicaid Services, 2011. http://www. hcahpsonline.org/Executive_Insight/Files/October2011HEl.pdf (accessed 27 Apr 2014).

26. De Wet C, McKay J, Bowie P. Combining QOF data with the care bundle approach may provide a more meaningful measure of quality in general practice. BMC Health Serv Res 2012;12:351.

27. Mulley A, Trimble C, Elwyn G. Patient preferences matter. The King's Fund, 2012. http://www.kingsfund.org.uk/sites/files/kf/field/ field_publication_file/patients-preferences-matter-may-2012.pdf (accessed 20 Jul 2014)

28. Royal College of General Practitioners. GP curriculum statements. London: RCGP, 2011. http://www.rcgp-curriculum.org.uk/rcgp_ curriculum_documents.aspx (accessed 4 Jul 2014).

29. Law S, Haman H, Cameron N, et al. GP peer appraisal in Scotland: an ongoing and developing exercise in quality. Educ Prim Care 2009;20:99-105.

30. NHS Scotland. Welcome to the Scottish Patient Safety Programme. Edinburgh: NHS Scotland, 2013. http://www scottishpatientsafetyprogramme.scot.nhs.uk/programme (accessed 5 Jul 2014).

31. Hankins M, Fraser A, Hodson A, et al. Measuring patient satisfaction for the quality and outcomes framework. $\mathrm{Br} J$ Gen Pract 2007;57:737-40.

32. Øvretveit J. Does improving quality save money? A review of the evidence of which improvements to quality reduce costs to health service providers. London: Health Foundation, 2009.

33. Health Foundation. Person-centred care made simple. London: Health Foundation, 2014. 